\title{
Fossils reject climate change as the cause of extinction of Caribbean bats
}

\section{CLIMATE-CHANGE ECOLOGY \\ ZOOLOGY}

Received

18 September 2014

Accepted

8 December 2014

Published

22 January 2015

Correspondence and requests for materials should be addressed to

J.A.S.-C. (asotocenteno@amnh.org)

\author{
J. Angel Soto-Centeno ${ }^{1,2}$ \& David W. Steadman ${ }^{2}$
}

'Department of Mammalogy, American Museum of Natural History, New York, NY 10024 USA, ${ }^{2}$ Department of Ornithology, Florida Museum of Natural History, University of Florida, Gainesville, FL 32611 , USA.

We combined novel radiocarbon dates of bat fossils with time-scaled ecological niche models (ENM) to study bat extinctions in the Caribbean. Radiocarbon-dated fossils show that late Quaternary losses of bat populations took place during the late Holocene $(<4 \mathrm{ka})$ rather than late Pleistocene $(>10 \mathrm{ka})$. All bat radiocarbon dates from Abaco (Bahamas) that represent extirpated populations are younger than $4 \mathrm{ka}$. We include data on six bat species, three of which are Caribbean endemics, and include nectarivores as well as insectivores. Climate-based ENMs from the Last Glacial Maximum to the present reflect overall stability in distributions, with suitable climatic habitat being present over time. In the absence of radiocarbon dates, bat extinctions had been presumed to take place during the last glacial-interglacial transition (ca. $10 \mathrm{ka}$ ). Now we see that extirpation of bats on these tropical islands is more complex than previously thought and primarily postdates the major climate changes that took place during the late Pleistocene-Holocene transition.

$\mathrm{T}$ he Caribbean islands, also known as the West Indies, once were home to at least 73 species of non-volant mammals (insectivores, primates, rodents, and sloths), all of which were endemic to one or few islands ${ }^{1-3}$. Sometime after the Last Glacial Maximum (LGM, ca. 25 to $18 \mathrm{ka}$ ), however, $79 \%-84 \%$ of the Caribbean land mammals became extinct ${ }^{4,5}$. It is estimated that humans arrived in the Caribbean about 7-6 ka and the effects of human activity for millennia after are well documented ${ }^{6,7}$. While various hypotheses have been proposed to explain the late Quaternary extinction of non-volant land mammals in the Caribbean, the timing of these losses is compatible with the concept that direct (e.g., hunting) and indirect (e.g., habitat modification) anthropogenic activities often were involved ${ }^{4,8,9}$.

In contrast to non-volant land mammals, bats (order Chiroptera) show much less extinction during the late Quaternary in the Caribbean, with an estimate that only ca. $18 \%$ of species (12 of 66) became extinct during that time $^{5,10}$. Extirpation (population-level loss) appears to have been more common than extinction (species-level loss) in Caribbean bats; $33 \%$ (22 of 66 species) of extant Caribbean bats are known to have lost a population from one or more islands ${ }^{5}$. The extirpations and extinctions of Caribbean bats have been attributed primarily to reductions in land area and changes in climate and habitat during the last glacial-interglacial transition (the Pleistocene-Holocene Transition, or PHT; centered on 11-9 ka), which included changes in island size and in the distribution of caves and cave environments associated with this climate change ${ }^{10,11}$.

The past 2.5 million years have been characterized by at least 22 glacial-interglacial cycles with rising and falling sea levels that caused major changes in island size, shape, and isolation ${ }^{12,13}$. Because the last glacial interval lies within the time that can be radiocarbon dated (up to ca. $50 \mathrm{ka}$ ), special attention has been given to the transition from the LGM (ca. 25-18 ka) cold climate to the warmer interglacial climate of the Holocene ${ }^{14}$ (HOL; ca. 10$0 \mathrm{ka})$.

Ecological niche models (ENMs; also called species distribution models, or SDMs) are used to estimate the relationship between species occurrence and the environmental and spatial characteristics where they occur ${ }^{15}$. ENMs are widely used to study biogeographic, conservation, ecological, and evolutionary questions ${ }^{16-18}$. ENM projections allow us to hindcast species distributions across time, which in combination with fossil data provide a strong framework to study extinctions and especially extirpations. In this paper, we examine previous hypotheses about the loss of insular bats using three ecologically distinct cave-dwelling species (Macrotus waterhousii, Monophyllus redmani, and Pteronotus parnellii) that overlap in distribution and have been subjected to extirpation in the Caribbean. Specifically, we combine radiocarbon dates on fossils with modern (present) and fossilvalidated past climate ENMs to provide new evidence on extirpation of Caribbean bats. If late Quaternary losses of these bats were driven by climate change during the PHT, then we predict that: 1) radiocarbon dated fossils from extirpated populations of bats should date to the PHT or older (i.e., $>9 \mathrm{ka}$ ); 2) model projections to the past 
Table $1 \mid$ Accelerator Mass Spectrometer (AMS) radiocarbon $\left({ }^{14} \mathrm{C}\right)$ dates for individual humeri representing extirpated populations of bats from Ralph's Cave, Abaco, The Bahamas ${ }^{a}$ and a single extant population from Trouing Jeremie, Départament-du-Sud, Haitib. Specimens from Ralph's Cave are listed in chronological order. All determinations were done at Beta Analytic, Inc., Miami, FL. For laboratory and calibration methods see www.radiocarbon.com

\begin{tabular}{lccccc} 
Species & Skeletal element & Sample number & $\delta^{13} \mathrm{C}(\%)$ & Conventional ${ }^{14} \mathrm{C}$ age (yr BP) & Calibrated ${ }^{14} \mathrm{C}$ age $(\mathrm{Cal} \mathrm{BP}, 2$ $\delta$ ) \\
\hline Monophyllus redmania $^{\mathrm{a}}$ & Humerus & Beta-358786 & -17.6 & $1810 \pm 30$ & $1820-1630$ \\
Pteronotus parnellii $^{\mathrm{a}}$ & Humerus & Beta-345516 & -18.0 & $3310 \pm 30$ & $3630-3460$ \\
Lasiurus minor $^{\mathrm{a}}$ & Humerus & Beta-360273 & -19.3 & $3580 \pm 30$ & $3690-3560$ \\
Natalus primus $^{\mathrm{a}}$ & Humerus & Beta-358785 & -18.4 & $3390 \pm 30$ & $3700-3570$ \\
Pteronotus parnellii $^{\text {a }}$ & Humerus & Beta-345515 & -18.6 & $3490 \pm 30$ & $3840-3690$ \\
Myotis austroriparius $^{\mathrm{a}}$ & Humerus & Beta-358784 & -18.5 & $3740 \pm 30$ & $4220-3990$ \\
Macrotus waterhousii $^{\mathrm{b}}$ & Humerus & Beta-345518 & -20.3 & $2030 \pm 30$ & $2060-1900$ \\
\hline
\end{tabular}

should approximate the distribution of fossils but not the present species distribution; and 3) availability of suitable climate as assessed by ENMs should be smaller in the present than in the LGM projections and have little overlap, resulting in no stability in distributions across time.

\section{Results}

Fossils and Last Appearance Radiocarbon Dates. Establishing the time of prehistoric extinctions requires accurate Last Appearance Radiocarbon Dates ${ }^{4,5,8}$ (LADs). Nonetheless, until now, direct LADs on individual bones have not been done for Caribbean bats; ${ }^{14} \mathrm{C}$ dates on other materials from various bat-bearing Caribbean fossil sites range from ca. 21,500 to $600 \mathrm{Cal} \mathrm{BP}^{19-22}$, although most sites with bat fossils remain undated, even indirectly. To address this situation, we obtained six new AMS ${ }^{14} \mathrm{C}$ dates from purified collagen of individual fossil humeri from five extirpated species of bats from Ralph's Cave on Abaco (Table 1; Fig. 1). For perspective, we also examined $2000+$ bat fossils (representing 20 species) from 20 fossil sites across the Greater Antilles and The Bahamas. Here we focus on the nine species from four families identified from Ralph's Cave, a site described by Steadman and Franklin ${ }^{23}$. Of the 97 fossil bat specimens from Ralph's Cave, 51 represent species that still exist on Abaco, namely Eptesicus fuscus (Big Brown Bat; $\mathrm{N}=18$ specimens), Chilonatalus tumidifrons (Bahamian Funnel-eared Bat; $\mathrm{N}=1$ ), Erophylla sezekorni (Buffy Flower Bat; $\mathrm{N}=2$ ), and Macrotus waterhousii (Waterhouse's Leaf-nosed Bat; $\mathrm{N}=30$ ). Five of these nine species are extirpated from Abaco, namely Monophyllus redmani (Greater Antillean Long-tongued Bat; $\mathrm{N}=2$ ), Pteronotus parnellii (Parnell's Mustached Bat; $\mathrm{N}=7$ ), Natalus primus (Cuban Funnel-eared Bat; $\mathrm{N}=18$ ), Lasiurus minor (Minor Red Bat; $\mathrm{N}=5$ ), and Myotis austroriparius (Southeastern Myotis; $\mathrm{N}=14$ ).

The six AMS ${ }^{14} \mathrm{C}$ dates that we determined for the five extirpated species were 1820-1690 Cal BP for Mo. redmani, 3840-3690 Cal BP and 3630-3460 Cal BP for P. parnellii, 3700-3570 Cal BP for $N$. primus, 3690-3560 Cal BP for L. minor, and 4220-3990 Cal BP for My. austroriparius (Table 1; Fig. 1). Each of these AMS ${ }^{14} \mathrm{C}$ dates is within the late Holocene, i.e., five to seven millennia after the time of glacial-interglacial changes in climate and island area. If we were to do more AMS ${ }^{14} \mathrm{C}$ dating of bat fossils from Ralph's Cave, it is likely that even younger dates than the ones reported would be determined for most if not all of the species.

Macrotus waterhousii, one of our focal species for ENMs, was identified from 30 fossils and still lives in Ralph's Cave, which indicates that it once shared this roost with the five extirpated species. We also identified five humeri of Ma. waterhousii in a small fossil sample from Trouing Jeremie, Haiti (Supplementary Fig. S1). This species still exists and is widespread on Hispaniola, although Trouing Jeremie is ca. $20 \mathrm{~km}$ from the nearest modern locality record for $M a$. waterhousii on the island. Ma. waterhousii is extirpated from Puerto Rico ${ }^{5,24}$. One humerus of $M a$. waterhousii from Trouing Jeremie (Haiti) was dated at 2060-1900 Cal BP (Table 1; Fig. 1), which is 5.5 to 7.4 ky younger than the three early Holocene AMS ${ }^{14} \mathrm{C}$ dates on sloth fossils from that site (see Methods and Ref. 8). This large difference in age illustrates the importance of doing direct AMC ${ }^{14} \mathrm{C}$ dates on bat fossils themselves rather than extrapolating their age from other dated materials.

Modern and Past Locality Records. The three focal species of bat vary in their modern and past distributions (Supplementary Fig. S1). We compiled 168 modern localities and 41 fossil localities for $M a$. waterhousii (Supplementary Fig. S1), which occurs today throughout The Bahamas, Cuba, Hispaniola, and Jamaica, and has been documented as a fossil on Puerto Rico, Anguilla, and Antigua ${ }^{1,5,10,24,25}$. We compiled 143 modern and 16 fossil localities for Mo. redmani (Supplementary Fig. S1), which now occurs in the Greater Antilles, Crooked and Acklins Islands (The Bahamas), and the Turks and Caicos Islands ${ }^{26}$, with a fossil record from Abaco (herein). We compiled 115 modern and 13 fossil localities for $P$. parnellii (Supplementary Fig. S1), which currently occurs throughout the Greater Antilles ${ }^{27}$ and also is widespread on the mainland from Mexico to Brazil ${ }^{28}$; it formerly occurred on Abaco and on Antigua $^{10,21,29}$ (also see Results herein).

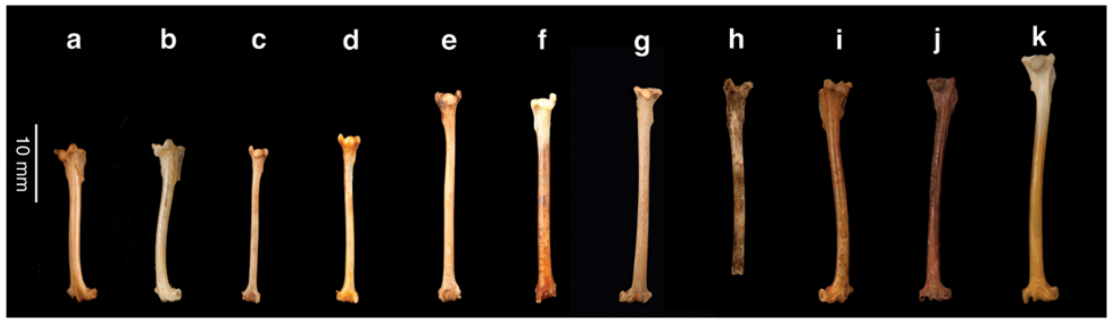

Figure 1 Bat humeri. (a), (c), (e), (g), and (j) are late Holocene fossils from Ralph's Cave, Abaco. (h) is a late Holocene fossil from Trouing Jeremie, Haiti. (b), (d), (f), (i), and (k) are modern specimens. Monophyllus redmani (a, b). Myotis austroriparius (c, d). Lasiurus borealis cf. minor (e, f). Natalus primus (g). Macrotus waterhousii (h, i). Pteronotus parnellii (j, k). Mo. redmani UF 14826, Haiti (b). My. austroriparius UF 24049, Florida (d). L. borealis cf. minor UF 30161, Florida (f). Ma. waterhousii UF 20812, Haiti (i). P. parnellii UF 6947, Guatemala (k). Fossil photographs by JAS-C. 
Table 2 | Overlap index (OI) and relative range size (RRS) estimates for Macrotus waterhousii, Monophyllus redmani, and Pteronotus parnellii on the Caribbean. Time of the predicted distributions is indicated as Current (CUR), Holocene (HOL), and Last Glacial Maximum (LGM). Threshold values were determined using the least training presence threshold LPT95\%. RRS for LGM distributions corrected for current island area are indicated with an asterisk (*). Negative RRS values indicate that the more recent range is bigger than the past (i.e. range expansion). Conversely, positive RRS values indicate that the more recent range is smaller than the past (i.e. range contraction)

\begin{tabular}{|c|c|c|c|c|c|c|c|}
\hline \multirow[b]{2}{*}{ Species } & \multirow[b]{2}{*}{ Threshold Value } & \multicolumn{3}{|c|}{$\mathrm{Ol}$} & \multicolumn{3}{|c|}{ RRS } \\
\hline & & CUR-HOL & HOL-LGM & CUR-LGM & CUR-HOL & HOL-LGM & CUR-LGM \\
\hline Ma. waterhousii & 0.2 & 0.893 & 0.592 & 0.531 & -0.116 & $\begin{array}{c}1.016 \\
-0.615 *\end{array}$ & $\begin{array}{c}0.806 \\
-0.803^{*}\end{array}$ \\
\hline Mo. redmani & 0.22 & 0.865 & 0.984 & 0.952 & -0.147 & $\begin{array}{c}1.718 \\
0.144^{*}\end{array}$ & $\begin{array}{c}1.369 \\
-0.002 *\end{array}$ \\
\hline P. parnellii & 0.15 & 0.729 & 0.890 & 0.830 & -0.308 & $\begin{array}{l}1.511 \\
0.141^{*}\end{array}$ & $\begin{array}{c}0.919 \\
-0.146 *\end{array}$ \\
\hline
\end{tabular}

Modern and Fossil-Validated Paleo-ENMs. ENMs inferring present distributions performed well for all three species of bat with average Area Under the Curve (AUC) values of $0.810 \pm 0.015$ for Ma. waterhousii, $0.829 \pm 0.018$ for Mo. redmani, and $0.791 \pm$ 0.015 for $P$. parnellii. Model projections to the HOL correctly predicted $87.5 \%$ and $92 \%$ of fossil localities of Mo. redmani and $P$. parnellii, respectively (Supplementary Fig. S2). In the case of $M a$. waterhousii, HOL model projections had a true positive fraction of $93 \%$.

The Effect of Climate on Species Distributions. The earth's climate underwent a dramatic shift from late Pleistocene glacial to Holocene interglacial conditions, with most of the change (especially in sea level) taking place during the PHT from 15 to $9 \mathrm{ka}^{14,30-32}$. The ca. $120 \mathrm{~m}$ rise in sea level during this period had a large effect on island area in much of the Caribbean ${ }^{33,34}$, which would have reduced the amount of terrestrial habitats, perhaps (on some islands) beyond the level needed to sustain viable populations of organisms ${ }^{11}$. Based on paleo-ENM projections, we observed changes in the relative range size of predicted habitat that indicate a range contraction from LGM to HOL, followed by a small range expansion from HOL to the present for all three species of bat (Table 2; Supplementary Fig. S2). Despite the trend of range change from past to present, the amount of overlap in the distributions across time was at least 53\% in Ma. waterhousii, $86 \%$ for Mo. redmani, and $72 \%$ for P. parnellii (Table 2). We represent these areas of overlap as stability maps, which include the intersection of distribution models across the three time periods for each species of bat (Fig. 2).

We also estimated Relative Range Size (RRS) and Overlap Index (OI) corrected for the current island area for each species to examine the distributional changes that have occurred on land areas that have not been affected by sea level change. For Ma. waterhousii, the corrected RRS suggest a very small contraction in range size from LGM to HOL, and also from HOL to the present. The high degree of overlap between $\mathrm{HOL}$ and present predicted distributions (i.e., $89 \%$ ) suggests that the available suitable habitat has remained nearly unchanged throughout the Holocene (Table 2; Fig. 2). RRS values corrected for island size in Mo. redmani and P. parnellii show a range contraction from LGM to HOL and an expansion from HOL to the present (Table 2; Supplementary Fig. S2). Nonetheless, the magnitude of these changes is small because the RRS estimates do not deviate much from zero, which would indicate no change in relative range over time.

\section{Discussion}

Bats often dominate modern Neotropical mammalian faunas in numbers of species and individuals ${ }^{35}$. Certainly they are the dominant order of native mammal in the Caribbean today. The integration of ENMs with large fossil datasets and last appearance radiocarbon dates provides a validated ecological explanation to examine community turnover in bats. Previous studies proposed that late Pleistocene climate change (and associated changes in habitat and island area) was the primary cause of extinction of Caribbean bats ${ }^{10,11}$. Here we provide evidence that extirpated populations of bats were able to persist on Abaco, the northernmost edge of the distribution in each species, for at least five to seven millennia after the last glacial-interglacial climate transition. These results contradict the climate change hypothesis and thus require alternative explanations for the extirpation and extinction of Caribbean bats.

We hypothesized that if late Quaternary losses of these bats were driven by climate change during the PHT, then radiocarbon dated fossils from extirpated populations of bats should be older than $9 \mathrm{ka}$. In spite of suggestions to the contrary ${ }^{10,11,19,20}$, the direct and associated AMS ${ }^{14} \mathrm{C}$ dates we present here show that extirpations took place into the late Holocene ( $<3.8 \mathrm{ka}$, in some cases $<1.8 \mathrm{ka}$ ). The late Holocene existence of these bat populations also suggests that late Pleistocene changes in the size and distribution of Bahamian caves and cave environments are unlikely causes for the extirpation of these populations. Furthermore, associated AMS ${ }^{14} \mathrm{C}$ dates presented by Steadman et al. ${ }^{21}$ and Pregill et al. ${ }^{29}$ show that two additional extirpated species (Pteronotus parnellii, Mormoops blainvillii) and an extinct one (Phyllonycteris major) were lost from Antigua no earlier than ca. 4300 to $1800 \mathrm{Cal} \mathrm{BP}$. If climatic changes during the PHT were the primary driver of the losses of Caribbean bats, it is difficult to understand why these species survived for at least 5000 years before becoming extinct.

ENMs have been successfully integrated with other approaches to estimate the magnitude of the effect that past climate change has had on various species ${ }^{17,36-38}$. The geographically explicit aspect of validated ENM projections over time provides an ideal method to examine biogeographic hypotheses about changes in the distribution of an organism in the face of major climatic changes. Our second goal was to develop rigorous ENMs that accurately represented the changes in distributions over time for three species of Caribbean bats. Our results of fossil-validated ENM projections to HOL and LGM climate for Ma. waterhousii, Mo. redmani, and P. parnellii were highly accurate with true positive fractions of $94 \%, 86 \%$, and $83 \%$, respectively. The paleo-ENMs confirmed the stability of suitable habitat in the past for all three species. Projections into present-day climate were also highly accurate with true positive fractions falling over $94 \%$. Therefore, we believe that our ENM projections adequately represent the potential distribution based on suitable habitat for each bat species across the Caribbean. Areas of distributional overlap across all three time periods represent areas of stability, which have been considered as refugia for some continental organisms ${ }^{17}$. For insular bats, areas of stability suggest that a considerable portion of the land area that has remained above water over time has been part of the suitable habitat available for each species to sustain viable populations 


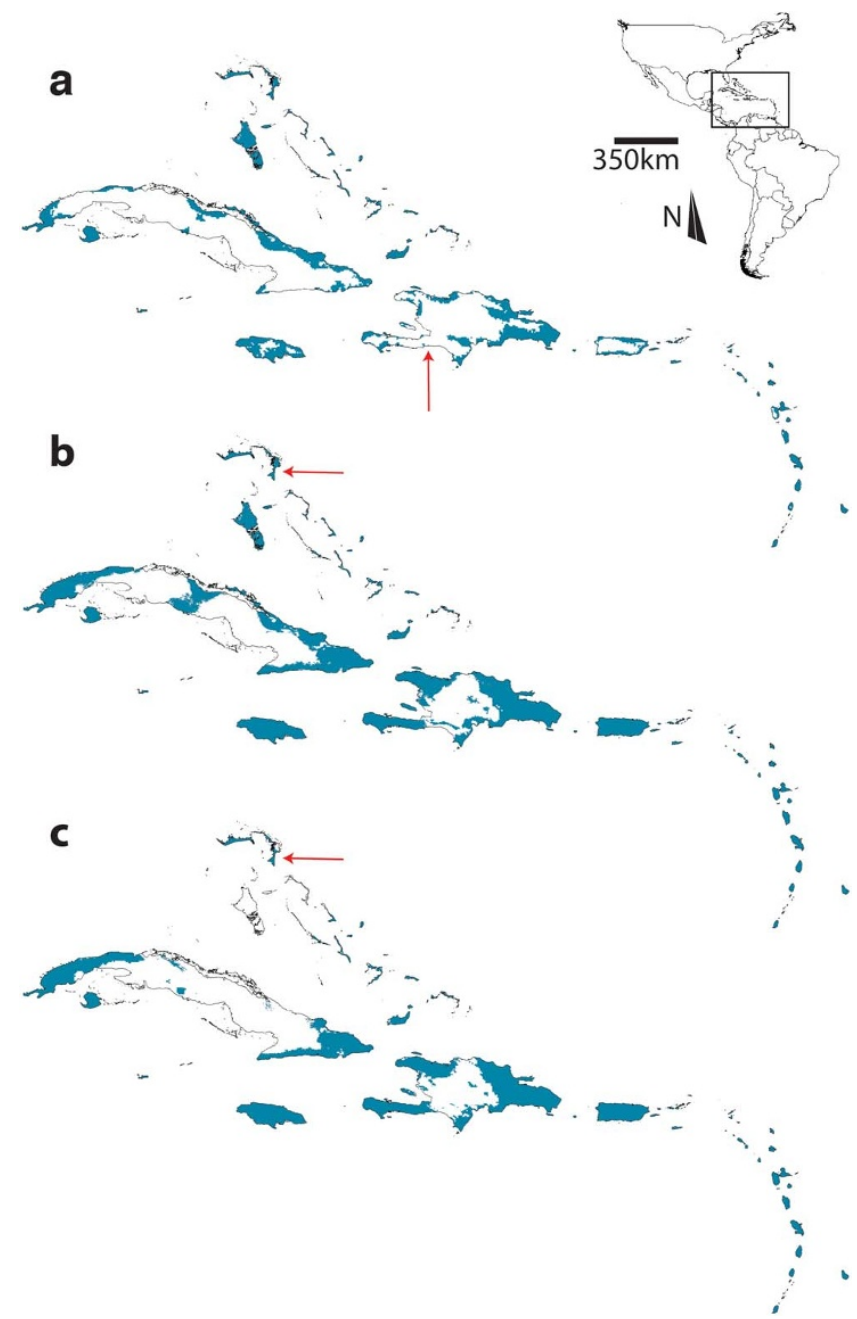

Figure $2 \mid$ Predicted habitat suitability across the West Indies for Macrotus waterhousii (a), Monophyllus redmani (b), and Pteronotus parnellii (c) represented as stability maps (i.e., the intersection of ecological niche model projections at three time periods: present, Holocene [ca. $6 \mathrm{ka}$ ], and Last Glacial Maximum [ca. 21 ka; LGM]). Predicted distributions were estimated in Maxent v3.3.3 and final maps created in ArcGIS v10.2. Blue shading indicates suitable areas where each species could have sustained viable populations across time. Red arrows indicate fossil localities for each species of bat used for radiocarbon estimation of last appearance dates (LAD) in this study.

(Fig. 2). These areas of stability include islands on which populations of bat have undergone recent extirpations. Therefore, we suggest that a reduction in geographic range from loss of island area does not necessarily lead to the loss of an island population.

The long-term stability in climatic niche observed in $M a$. waterhousii, Mo. redmani, and P. parnellii is consistent with the assumption of niche conservatism ${ }^{39,40}$. Furthermore, our results are consistent with a recent study suggesting that some mainland North American mammal distributions show remarkably stable range sizes from late Pleistocene to late Holocene despite range shifts and extirpations in others ${ }^{41}$. The one to two-fold change in RRS values are evidence of the effect of sea level rise on the loss of potentially suitable habitat for these three species of bats. After correcting for island area, indices of RRS and OI for all three species suggest that little change in the available suitable habitat took place during this climate transition (i.e., the PHT). Even though these RRS changes were small, they do support the hypothesis that reductions in land area and changes in climate and habitat during the last glacial-interglacial transition did affect Ma. waterhousii, Mo. redmani, and P. parnellii populations.
Despite this, overlap in suitable habitat for all three species of bat was at least $73 \%$ between the HOL and the present, and at least $60 \%$ between LGM and HOL on land that lies above sea level today.

It is important to note that the island groups where bat extirpations have been documented and radiocarbon dated (see Results, Steadman et al. ${ }^{21}$, and Pregill et al. ${ }^{29}$ ) had over $80 \%$ reduction in island area from LGM to the present (Supplementary Table S1). Our ENM results show that, even when a Caribbean island underwent a considerable reduction of land area during the PHT (considering the estimated low sea level of $-135 \mathrm{~m}$ for the $\mathrm{LGM}^{42}$ ), the minimum amount of suitable habitat to sustain viable populations of Ma. waterhousii, Mo. redmani, and P. parnellii probably was unchanged. Although we recognize that reductions in the population sizes of Ma. waterhousii (Puerto Rico) and of Mo. redmani and P. parnellii (Bahamas) probably took place during the PHT, we find it unlikely that reduced island area alone would have eliminated these or any of the other bat populations that survived into the late Holocene but now are gone.

Prehistoric (and historic) human impacts on island species and ecosystems feature considerable habitat alteration, especially when the prehistoric peoples were horticulturalists who altered natural fire regimes on large scales ${ }^{43-45}$ as in the Bahamas, where Amerindians first colonized from 1.5 to $1.0 \mathrm{ka}^{44,46}$. Bat extirpations documented for the northern Lesser Antilles ${ }^{21}$ occurred following a period of increased anthropogenic activity (ca. $5300 \mathrm{Cal} \mathrm{BP}$ ) that is well documented on the nearby island of Puerto Rico ${ }^{7,47}$. Therefore, it seems plausible that human-induced habitat changes contributed to the extirpation of bats of the northern Lesser Antilles. While the precise mechanism leading to extirpation (e.g., direct predation, habitat loss, invasive plants and animals, etc.) is undetermined, the late Holocene demise of bat populations in the Bahamas coincides with similar land mammal, reptile, and bird losses on other Caribbean islands $s^{7,23,48}$.

The radiocarbon dates we present here, combined with climate ENMs, demonstrate that at least five species of bats withstood climate change and reduced land area during the Pleistocene-Holocene Transition on Abaco, only to become extirpated during the late Holocene, a time when climate conditions were largely similar to those of today ${ }^{49}$. Because Abaco (and other Bahamian islands) lost a much greater proportion of its land during the PHT sea-level rise than Greater Antillean islands ${ }^{23}$, we would expect that new research will discover that most extirpated populations or extinct species of bats in the Caribbean also survived well into the Holocene. We challenge other researchers (and ourselves) to develop a more comprehensive extinction chronology for Caribbean bats through additional AMS ${ }^{14} \mathrm{C}$ dating. Only in this way will we be able to make archipelago-wide generalizations about when the numerous populations and species were lost.

\section{Methods}

Modern and Fossil Localities. Locality records with WGS84 latitude/longitude coordinates were obtained for modern specimens of Macrotus waterhousii (Waterhouse's Leaf-nosed Bat), Monophyllus redmani (Greater Antillean Longtongued Bat), and Pteronotus parnellii (Parnell's Mustached Bat) with GPS in the field and from the MaNIS database (http://manisnet.org). Each of these species is ecologically distinct. For example, among cave dwelling species, Ma. waterhousii prefers the use of cool caves, whereas Mo. redmani and P. parnellii prefer hot caves. Similarly, these bats fit in different dietary guilds, with $M a$. waterhousii as a gleaning insectivore, Mo. redmani primarily a nectarivore, and $P$. parnellii a hawking insectivore. Bat fossils (cataloged in the Vertebrate Paleontology Collection, Florida Museum of Natural History, University of Florida; UF) were identified to species by comparing them to modern bones (especially humeri, mandibles, and skulls) from the UF Mammalogy Collection. Fossil occurrences of all three species were georeferenced following the guidelines of MaNIS. Additional (non-UF) fossil localities for each species were obtained from the literature, and then georeferenced. Every locality representing an extirpated population was included in the fossil datasets to evaluate the performance of the paleo-ENMs. We plotted distributions for the three species of bat separately in ARCGIS v10.2 (ESRI, Redlands, CA) to visually assess the quality of spatial data and to correct erroneously georeferenced localities to the nearest $0.001^{\circ}$ following their locality description. 
Table 3 Model performance statistics based on AICc for the best and default Ecological Niche Models of three species of West Indian bats. Performance statistics were estimated using ENMtools (Warren et al. 2010). Selected model features include: quadratic (Q), product (P), hinge (H), and threshold (T). Model testing statistics are negative log likelihood (-InL) and sample size corrected Akaike Information Criterion (AICc)

Species

Model

Parameters

$-\ln L$

$\mathrm{AlCc}$

Macrotus waterhousii

QPH features

22
33

Auto features

3974.89

$-4047.91$

QPT features

$-3635.49$

$-3680.78$

QPH features

29

31

$-3614.24$

Auto features

18

$-3614.42$

7997.25

8169.82

7335.37

7430.91

7266.91

7271.83

Last Appearance Radiocarbon Dates (LADs). Last Appearance Radiocarbon Dates (LADs) represent the latest dated records of a population or species, and as such can provide useful conservative estimates of the time of extirpation or extinction ${ }^{8,9}$. From two fossil localities (Ralph's Cave, Abaco, Bahamas, $26.24961^{\circ} \mathrm{N},-77.19021^{\circ} \mathrm{W}$; and Trouing Jeremie, Départament-du-Sud, Haiti, $\left.18.20999^{\circ} \mathrm{N},-74.01001^{\circ} \mathrm{W}\right)$, we established a chronology based on Accelerator Mass Spectrometer (AMS) radiocarbon $\left({ }^{14} \mathrm{C}\right)$ dates from purified collagen of individual fossil bat humeri. For laboratory and analytical methods see references ${ }^{50,51}$. We obtained direct (singlespecimen) AMS ${ }^{14} \mathrm{C}$ dates for $M a$. waterhousii (Trouing Jeremie; extant population) and for five extirpated populations from Ralph's Cave - Mo. redmani, P. parnellii, Natalus primus, Lasiurus minor, and Myotis austroriparius.

The bat fossils that we examined from Trouing Jeremie are from a site with a Holocene chronology based on three AMS ${ }^{14} \mathrm{C}$ dates from purified collagen extracted from different individual bones of the extinct sloth Neocnus comes ${ }^{8}$. These dates ranged from 9490-9130 Cal BP to 7790-7610 Cal BP (early Holocene). We selected one humerus from $\mathrm{Ma}$. waterhousii to the date the occurrence of this bat at Trouing Jeremie.

Ecological Niche Modeling (ENM). We used presence-only data analyzed in a maximum entropy approach to develop present and paleo-ecological niche models (paleo-ENMs) for Ma. waterhousii, Mo. redmani, and P. parnellii. We used climate data from 19 WorldClim variables for present climate, the Holocene (HOL; ca. 6 ka), and the Last Glacial Maximum ${ }^{52}$ (LGM; ca. $21 \mathrm{ka}$ ). The use of two time periods in the past allowed us to reconstruct distributions at a similar but possibly wetter and slightly warmer period (HOL) and at a cooler and drier period (LGM) compared to present conditions ${ }^{53,54}$. Both paleo-climate conditions were obtained from statistically downscaled estimates of past conditions from the ESCHAM3 and MIROC models available from WorldClim (see www.worldclim.org for downscaling details). We used ESCHAM3 and MIROC models because they showed good performance in previous paleo-climate reconstructions ${ }^{55}$. The three climate data sets were clipped to a regional extent of the Caribbean using ARCGIS v10.2. To correct for co-linearity among the 19 climate variables, we performed a Pearson Correlation in R v2.15.0 (correlation coefficient $>0.8 ; 24)$ and removed correlated climatic variables for each time period. The resulting datasets feature seven uncorrelated climatic variables that represent the climate of the Caribbean (Temperature - bio1, annual mean; bio2, mean diurnal range; bio3, isothermality; bio7, annual range; and Precipitation - bio12, annual; bio14, driest month; bio18, warmest quarter). We extracted present climate information for our species data and for a random background climate dataset of 1250 points to sample the accessible area of background climate for each species of bat. Random background points that were within $1 \mathrm{~km}$ of a species locality record were removed. This restriction of background is recommended to reduce error in model parameterization, validation, and comparison ${ }^{57}$.

We generated ENMs using MAXENT v3.3.3 because its predictive performance is consistently high compared to that of other methods ${ }^{58-60}$. We randomly partitioned species localities into $75 \%$ training and $25 \%$ testing datasets with 100 bootstrap replicates to evaluate model performance. To ensure appropriate model parameterization, we developed multiple ENMs combining different features in MAXENT and evaluated the complexity of each model using AICc implemented in ENMTOOLS v.1.4. $3^{61,62}$. The parameters used in the final ENMs included a regularization multiplier of 1 , and a combination of quadratic, product, threshold, and hinge features (Table 3). We projected all ENMs to present, HOL, and LGM background climate for the West Indies to obtain our final models.

Evaluation of model performance for each species of bat was assessed using the area under the receiving operating characteristic curve (AUC). AUC is a threshold independent measure that varies from 0 to 1 , where a score of 1 represents perfect discrimination and a score of 0.5 represents a model no better than random ${ }^{56}$. We considered an AUC score $>0.7$ to represent good model predictions ${ }^{56,63,64}$. Some authors question the accuracy of AUC for evaluating model performance ${ }^{65}$ (e.g., when using presence only data). Therefore, we also quantified model overfitting directly by comparing threshold-dependent omission rates with theoretical omission levels ${ }^{66}$. We applied a lowest presence threshold rule of 95\% (LPT95\%) to the average models from MAXENT logistic output ${ }^{38,67}$. Under this rule, pixels with values equal or higher than the selected threshold were considered as suitable conditions for a species to sustain viable populations, which allowed us to generate binary (i.e., presence/ absence) predictions. We chose LPT95\% because it is a relaxed threshold for which predicted model training datasets resulted in at least $95 \%$ of locality points contained within suitable habitat ${ }^{38,67}$ (i.e., a $5 \%$ omission rate). The use of a relaxed threshold when generating past ENM projections allowed enough sensitivity to determine longterm suitable areas where species could maintain viable populations over time. The resulting presence-absence distribution maps for the three time periods of each species were summed and corrected for the present island area to develop stability maps (Fig. 2). Predicted areas of stability represent areas where each species is predicted to occur across the present, HOL, and LGM time periods. All range estimates were performed in ARCGIS v10.2.

Validation and Evaluation of Models Across Time. Paleo-ENMs were developed as model projections onto HOL and LGM climate using modern locality records. Therefore, paleo-ENMs cannot be evaluated based on AUC alone. We were interested in assessing how accurately our paleo-ENMs could predict the fossil locality data because inferences on how climate change affects an organism depend on how well the model can predict potential distributions in the past. For this assessment, we estimated the true positive fraction (i.e., correctly predicted fossil localities) to determine the fit of paleo-ENM projections over time for each species of bat.

We used the LPT95\%-transformed models to evaluate the effects of climate change on each species of bat from the present and paleo-ENMs by estimating two indices: relative range size (present $\geq$ past $R R S=c / m-1$, or present $\leq$ past $R R S=-1 \times$ $[\mathrm{m} / \mathrm{c}-1])$ and overlap index $(\mathrm{OI}=o / m$; where $m=$ present climate conditions, $c=$ past climate conditions, and $o=$ amount of overlap between present and paleoENMs $)^{68}$. We used RRS to compare the size and magnitude of change of predicted present vs. paleo-ENMs. A negative RRS value implies that the paleo-distribution was smaller than the present distribution, a positive RRS value implies that the paleodistribution was larger than at present, and a value of zero indicates no change ${ }^{68}$. OI was used to determine the magnitude of overlap between present and paleodistributions. Overlap in predicted distributions relates to areas that remained climatically suitable and could have provided suitable habitat where bat populations persisted over time. Because eustatic sea level changes caused major changes in land area for many Caribbean islands, we also estimated RRS and OI values corrected for the present-day area of the islands to isolate the effect of changes in island area on species distributions. These corrected estimates of the persistence of suitable climate and habitat are associated with areas that may have been occupied by each species throughout the late Quaternary.

1. Morgan, G. S. \& Woods, C. A. Extinction and the zoogeography of West Indian land mammals. Biol. J. Linn. Soc. 28, 167-203 (1986).

2. MacPhee, R. D. E. \& Flemming, C. in Extinctions near time: causes, context, and consequences (MacPhee, R. D. E.) 333-367 (Kluwer Academic, 1999).

3. Hedges, S. B. in Biogeography of the West Indies: patterns perspectives (Woods, C. A. \& Sergile, F. E.) 15-33 (CRC Press, 2001).

4. MacPhee, R. D. E. in American megafaunal extinctions at the end of the Pleistocene (Haynes, G.) 169-193 (Springer, 2009).

5. Dávalos, L. M. \& Turvey, S. T. in Bones, clones and biomes: the history and geography of recent Neotropical mammals (Patterson, B. D. \& Costa, L. P.) 157-202 (University of Chicago Press, 2012).

6. Fitzpatrick, S. M. \& Keegan, W. F. Human impacts and adaptations in the Caribbean Islands: an historical ecology approach. Trans. R. Soc. Edinburgh Earth Sci. 98, 29-45 (2007).

7. Turvey, S. T., Oliver, J. R., Narganes Storde, Y. M. \& Rye, P. Late Holocene extinction of Puerto Rican native land mammals. Biol. Lett. 3, 193-6 (2007).

8. Steadman, D. W. et al. Asynchronous extinction of late Quaternary sloths on continents and islands. Proc. Natl. Acad. Sci. USA 102, 11763-11768 (2005).

9. MacPhee, R. D. E., Iturralde-Vinent, M. A. \& Jiménez-Vázquez, O. Prehistoric sloth extinctions in Cuba: implications of a new "Last Appearance Date." Caribb. J. Sci. 43, 94-98 (2007).

10. Morgan, G. S. in Biogeography of the West Indies: patterns perspectives (Woods, C. A. \& Sergile, F. E.) 369-408 (CRC Press, 2001).

11. Dávalos, L. M. \& Russell, A. L. Deglaciation explains bat extinction in the Caribbean. Ecol. Evol. 2, 3045-3051 (2012).

12. Lambeck, K. \& Chappell, J. Sea level change through the last glacial cycle. Science 292, 679-686 (2001). 
13. Cuffey, K. \& Marshall, S. Substantial contribution to sea-level rise during the last interglacial from the Greenland ice sheet. Nature 404, 591-594 (2000).

14. Denton, G. H. et al. The last glacial termination. Science 328, 1652-1656 (2010).

15. Franklin, J. Mapping species distributions: spatial inference and predictions. 317 (Cambridge University Press, 2009).

16. Waltari, E. \& Hickerson, M. J. Late Pleistocene species distribution modelling of North Atlantic intertidal invertebrates. J. Biogeogr. 40, 249-260 (2012).

17. Carnaval, A. C., Hickerson, M. J., Haddad, C. F. B., Rodrigues, M. T. \& Moritz, C. Stability predicts genetic diversity in the Brazilian Atlantic forest hotspot. Science 323, 785-789 (2009).

18. Soto-Centeno, J. A., Barrow, L. N., Allen, J. M. \& Reed, D. L. Reevaluation of a classic phylogeographic barrier: new techniques reveal the influence of microgeographic climate variation on population divergence. Ecol. Evol. 3, 1603-1613 (2013).

19. Suárez, W. \& Díaz-Franco, S. A new fossil bat (Chiroptera: Phyllostomidae) from a Quaternary cave deposit in Cuba. Caribb. J. Sci. 39, 371-377 (2003).

20. Jiménez-Vázquez, O., Condis, M. M. \& García-Cancio, E. Vertebrados postglaciales en un residuario fosil de Tyto alba scopoli (Aves: Tytonidae) en el occidente de Cuba. Rev. Mex. Mastozool. 9, 85-112 (2005).

21. Steadman, D. W., Pregill, G. K. \& Olson, S. L. Fossil vertebrates from Antigua, Lesser Antilles: evidence for late Holocene human-caused extinctions in the West Indies. Proc. Natl. Acad. Sci. USA 81, 4448-4451 (1984).

22. Steadman, D. W. \& Takano, O. M. A late-Holocene bird community from Hispaniola: refining the chronology of vertebrate extinction in the West Indies. The Holocene 23, 936-944 (2013).

23. Steadman, D. W. \& Franklin, J. Changes in a West Indian bird community since the late Pleistocene. J. Biogeogr. DOI:10.1111/jbi.12418 (2014).

24. Choate, J. R. \& Birney, E. C. Sub-recent Insectivora and Chiroptera from Puerto Rico, with the description of a new bat of the genus Stenoderma. J. Mammal. 49, 400-412 (1968).

25. Anderson, S. Macrotus waterhousii. Mamm. Species 1, 1-4 (1969).

26. Homan, J. A. \& Jones, J. K. Monophyllus redmani. Mamm. Species 57, 1-3 (1975).

27. Herd, R. M. Pteronotus parnellii. Mamm. Species 209, 1-5 (1983).

28. Clare, E. L. et al. Diversification and reproductive isolation: cryptic species in the only New World high-duty cycle bat, Pteronotus parnellii. BMC Evol. Biol. 13, 26 (2013).

29. Pregill, G. K., Steadman, D. W., Olson, S. L. \& Grady, F. V. Late Holocene fossil vertebrates from Burma Quarry, Antigua, Lesser Antilles. Smithson. Contrib. Zool. 463, 1-27 (1988).

30. Clark, P. U. \& Mix, A. C. Global change: ice sheets by volume. Nature 406, 689-690 (2000).

31. Bard, E., Hamelin, B. \& Delanghe-Sabatier, D. Deglacial meltwater pulse 1B and Younger Dryas sea levels revisited with boreholes at Tahiti. Science 327, 1235-1237 (2010).

32. Yokoyama, Y., Lambeck, K., De Deckker, P., Johnston, P. \& Fifield, L. Timing of the Last Glacial Maximum from observed sea-level minima. Nature 406, 713-716 (2000).

33. Blanchon, P. \& Shaw, J. Reef drowning during the last deglaciation: evidence for catastrophic sea-level rise and ice-sheet collapse. Geology 23, 4-8 (1995).

34. Taylor, K. C. et al. The "flickering switch" of late Pleistocene climate change. Nature 361, 432-436 (1993).

35. Voss, R. S. \& Emmons, L. H. Mammalian diversity in Neotropical lowland rainforests: a preliminary assessment. Bull. Am. Museum Nat. Hist. 230, 115 (1996).

36. Waltari, E. et al. Locating pleistocene refugia: comparing phylogeographic and ecological niche model predictions. PLoS One 2, e563 (2007).

37. Buckley, T. R., Marske, K. A. \& Attanayake, D. Identifying glacial refugia in a geographic parthenogen using palaeoclimate modelling and phylogeography: the New Zealand stick insect Argosarchus horridus (White). Mol. Ecol. 18, 4650-4663 (2009).

38. Waltari, E. \& Guralnick, R. P. Ecological niche modelling of montane mammals in the Great Basin, North America: examining past and present connectivity of species across basins and ranges. J. Biogeogr. 36, 148-161 (2009).

39. Peterson, A. T., Soberón, J. \& Sánchez-Cordero, V. Conservatism of ecological niches in evolutionary time. Science 285, 1265-1267 (1999).

40. Peterson, A. T. Ecological niche conservatism: a time-structured review of evidence. J. Biogeogr. 38, 817-827 (2011).

41. Hadly, E. A., Spaeth, P. A. \& Li, C. Niche conservatism above the species level. Proc. Natl. Acad. Sci. USA 106, 19707-19714 (2009).

42. Rohling, E. J. et al. Magnitudes of sea-level lowstands of the past 500,000 years. Nature 394, 162-166 (1998).

43. Kjellmark, E. Late Holocene climate change and human disturbance on Andros Island, Bahamas. J. Paleolimnol. 15, 133-145 (1996).

44. Keegan, W. F. Taino Indian myth and practice: the arrival of the stranger king. 256 (University Press of Florida, 2007).

45. Steadman, D. W. et al. Exceptionally well preserved late Quaternary plant and vertebrate fossils from a blue hole on Abaco, The Bahamas. Proc. Natl. Acad. Sci. USA 104, 19897-19902 (2007).

46. Berman, M. J. \& Gnivecki, P. L. The colonization of the Bahama archipelago: a reappraisal. World Archaeol. 26, 421-441 (1995).
47. Burney, D. A., Burney, L. P. \& MacPhee, R. D. E. Holocene charcoal stratigraphy from Laguna Tortuguero, Puerto Rico, and the timing of human arrival on the island. J. Archaeological Sci. 21, 273-281 (1994).

48. Steadman, D. W. et al. Late-Holocene faunal and landscape change in the Bahamas. The Holocene 24, 220-230 (2014).

49. Lambeck, K., Esat, T. M. \& Potter, E. K. Links between climate and sea levels for the past three million years. Nature 419, 199-206 (2002).

50. Stafford, T. W., Hare, E. P., Currie, L. A., Jull, A. J. T. \& Donahue, D. Accelerator radiocarbon dating at the molecular level. J. Archaeol. Sci. 18, 35-72 (1991).

51. Jull, A. J. T. in Encyclopedia of Quaternary Science (Elias, S.) 2911-2918 (Elsevier, 2006).

52. Hijmans, R. J., Cameron, S. E., Parra, J. L., Jones, P. G. \& Jarvis, A. Very high resolution interpolated climate surfaces for global land areas. Int. J. Climatol. 25, 1965-1978 (2005).

53. Clark, P. U. et al. The Last Glacial Maximum. Science 325, 710-714 (2009).

54. Hodell, D. A. et al. Reconstruction of Caribbean climate change over the past 10,500 years. Nature 352, 790-793 (1991)

55. Braconnot, P. et al. Results of PMIP2 coupled simulations of the Mid-Holocene and Last Glacial Maximum - Part 1: experiments and large-scale features. Clim. Past 3, 261-277 (2007).

56. Peterson, A. T. et al. Ecological niches and geographic distributions. 316 (Princeton University Press, 2011).

57. Barve, N. et al. The crucial role of the accessible area in ecological niche modeling and species distribution modeling. Ecol. Modell. 222, 1810-1819 (2011).

58. Phillips, S., Anderson, R. \& Schapire, R. Maximum entropy modeling of species geographic distributions. Ecol. Modell. 190, 231-259 (2006).

59. Elith, J. et al. A statistical explanation of MaxEnt for ecologists. Divers. Distrib. 17, 43-57 (2011)

60. Elith, J. et al. Novel methods improve prediction of species' distributions from occurrence data. Ecography 29, 129-151 (2006).

61. Warren, D. L., Glor, R. E. \& Turelli, M. ENMTools: a toolbox for comparative studies of environmental niche models. Ecography 33, 607-611 (2010).

62. Warren, D. L. \& Seifert, S. N. Ecological niche modeling in Maxent: the importance of model complexity and the performance of model selection criteria. Ecol. Appl. 21, 335-342 (2011).

63. Swets, J. A. Measuring the accuracy of diagnostic systems. Science 240, 1285-1293 (1988).

64. Allouche, O., Tsoar, A. \& Kadmon, R. Assessing the accuracy of species distribution models: prevalence, kappa and the true skill statistic (TSS). J. Appl. Ecol. 43, 1223-1232 (2006).

65. Lobo, J. M., Jiménez-Valverde, A. \& Real, R. AUC: a misleading measure of the performance of predictive distribution models. Glob. Ecol. Biogeogr. 17, 145-151 (2008).

66. Radosavljevic, A. \& Anderson, R. P. Making better Maxent models of species distributions: complexity, overfitting and evaluation. J. Biogeogr. 41, 629-643 (2014).

67. Pearson, R. G., Raxworthy, C. J., Nakamura, M. \& Peterson, A. T. Predicting species distributions from small numbers of occurrence records: a test case using cryptic geckos in Madagascar. J. Biogeogr. 34, 102-117 (2007).

68. Hijmans, R. J. \& Graham, C. H. The ability of climate envelope models to predict the effect of climate change on species distributions. Glob. Chang. Biol. 12, 2272-2281 (2006).

\section{Acknowledgments}

We appreciate the strong foundation for the paleontology of Caribbean bats developed through the years by Gary Morgan and the late Karl Koopman. For their efforts in the field or laboratory, we also thank Nancy Albury, Kenny Broad, Daniel Cordier, Kelly Delancy, Janet Franklin, Richard Franz, Richard Hulbert, Brian Kakuk, Jim Mead, Gary Morgan, Hayley Singleton, and Charles Woods. This research was supported by the National Science Foundation (grant BCS-1118369 to DWS), National Geographic Society (grant EC0372-08), and the UF Ornithology Endowment. Part of this research was also funded by AMNH Theodore Roosevelt Postdoctoral Fellowship and a Gerstner Scholarship to JAS-C. Research permits and other important logistical assistance were kindly provided by The Bahamas National Trust (Eric Carey, Markus Davis, Lynn Gape, David Knowles), Abaco Friends of the Environment (Michael Albury, Ruth Albury, Olivia Patterson, Kristin Williams), The National Museum of The Bahamas (Antiquities, Monuments and Museums Corporation) (Nancy Albury, Kelly Delancy, Michael Pateman, Keith Tinker), and Bahamas Caves Research Foundation (Brian Kakuk). JAS-C thanks Aja Marcato and Ron Barrilito for additional logistic support and stimulating conversations about extinctions. We are especially grateful to Brian Kakuk and Nancy Albury for doing or coordinating the scuba diving to collect fossils in flooded caves. For comments that improved the manuscript, we thank Susan Cameron Devitt, Janet Franklin, Jessica Oswald, and David Reed.

\section{Author contributions}

J.A.S.-C. and D.W.S. conceived the ideas. J.A.S.-C. analyzed the data. J.A.S.-C. and D.W.S. co-wrote the paper. Both authors reviewed the manuscript. 


\section{Additional information}

Supplementary information accompanies this paper at http://www.nature.com/ scientificreports

Competing financial interests: The authors declare no competing financial interests.

How to cite this article: Soto-Centeno, J.A. \& Steadman, D.W. Fossils reject climate change as the cause of extinction of Caribbean bats. Sci. Rep. 5, 7971; DOI:10.1038/srep07971 (2015). (i) $\Theta$ This work is licensed under a Creative Commons Attribution-NonCommercialNoDerivs 4.0 International License. The images or other third party material in this article are included in the article's Creative Commons license, unless indicated otherwise in the credit line; if the material is not included under the Creative Commons license, users will need to obtain permission from the license holder in order to reproduce the material. To view a copy of this license, visit http:// creativecommons.org/licenses/by-nc-nd/4.0/ 